University of Wollongong

Research Online

Faculty of Informatics - Papers (Archive)

Faculty of Engineering and Information

Sciences

2010

\title{
Harmonic allocation following IEC guidelines using the voltage droop concept
}

\author{
V. J. Gosbell \\ University of Wollongong, vgosbell@uow.edu.au \\ Robert A. Barr \\ University of Wollongong, rbarr@uow.edu.au
}

Follow this and additional works at: https://ro.uow.edu.au/infopapers

Part of the Physical Sciences and Mathematics Commons

\section{Recommended Citation}

Gosbell, V. J. and Barr, Robert A.: Harmonic allocation following IEC guidelines using the voltage droop concept 2010.

https://ro.uow.edu.au/infopapers/3510

Research Online is the open access institutional repository for the University of Wollongong. For further information contact the UOW Library: research-pubs@uow.edu.au 


\title{
Harmonic allocation following IEC guidelines using the voltage droop concept
}

\author{
Abstract \\ Present IEC guidelines are difficult to apply to realistic cases because of the data load, the number of \\ assumptions required and the computational complexity. A new approach is given based on the concept \\ of voltage droop, to be detailed in a companion paper. The benefits of the approach are a simple \\ calculation with minimal data and no required assumptions. It applies to radial or meshed distribution \\ systems where feeders are sufficiently short that line capacitance can be ignored. The approach can be \\ applied at the installation (MV or LV) and the equipment level and can be used to give reference values for \\ equipment emission standards. \\ Disciplines \\ Physical Sciences and Mathematics \\ Publication Details \\ Gosbell, V. J. \& Barr, R. A. (2010). Harmonic allocation following IEC guidelines using the voltage droop \\ concept. 14th International Conference on Harmonics and Quality of Power, ICHQP 2010 (pp. 1-6). \\ Bergamo, Italy: IEEE.
}




\title{
Harmonic Allocation Following IEC Guidelines Using the Voltage Droop Concept
}

\author{
V.J. Gosbell, Life Member, IEEE and R.A. Barr, Member, IEEE
}

\begin{abstract}
Present IEC guidelines are difficult to apply to realistic cases because of the data load, the number of assumptions required and the computational complexity. A new approach is given based on the concept of voltage droop, to be detailed in a companion paper. The benefits of the approach are a simple calculation with minimal data and no required assumptions. It applies to radial or meshed distribution systems where feeders are sufficiently short that line capacitance can be ignored. The approach can be applied at the installation (MV or $L V)$ and the equipment level and can be used to give reference values for equipment emission standards.
\end{abstract}

Index Terms-- distribution systems, harmonics, IEC standards, IEEE standards, harmonic allocation, voltage drop.

\section{NOMENCLATURE}

\begin{tabular}{|l|l|}
\hline \multicolumn{1}{|c|}{ Symbol } & \multicolumn{1}{c|}{ Meaning } \\
\hline $\mathrm{E}_{\mathrm{hhi}}$ & Allocated harmonic current at order h to load "i" \\
\hline $\mathrm{E}_{\mathrm{Uhi}}$ & Allocated harmonic voltage at order h to load "i" \\
\hline $\mathrm{G}_{\mathrm{MVh}}$ & Available harmonic voltage at MV level \\
\hline $\mathrm{h}$ & Harmonic order \\
\hline $\mathrm{i}$ & Subscript referring to load "i" \\
\hline $\mathrm{I}_{\mathrm{ih}}$ & Harmonic current drawn by load \\
\hline $\mathrm{k}_{\mathrm{h}}$ & Harmonic allocation constant \\
\hline $\mathrm{L}_{\mathrm{LVh}}$ & Planning level for harmonic $\mathrm{h}$ at LV \\
\hline $\mathrm{SCR}_{\mathrm{R}}$ & Short circuit ratio \\
\hline $\mathrm{S}_{\mathrm{i}}$ & Maximum demand of load \\
\hline $\mathrm{S}_{\mathrm{t}}$ & Sum of all substation loads requiring a harmonic allocation \\
\hline $\mathrm{V}_{\mathrm{droop}}$ & System voltage droop \\
\hline $\mathrm{V}_{\mathrm{ih}}$ & Harmonic voltage caused by load at point of connection \\
\hline $\mathrm{x}_{\mathrm{ih}}$ & Harmonic reactance \\
\hline$\alpha$ & Exponent representing diversity \\
\hline
\end{tabular}

\section{INTRODUCTION}

$\mathrm{H}$ armonics in power systems have been an issue over many decades, with Standards Australia publishing its first harmonic standard AS 2279.2 in 1979 [1]. Excess harmonic voltage levels can lead to additional losses and possible overheating of induction motors and shunt-connected capacitors. High harmonic currents from single phase equipment in three phase installations can lead to unexpectedly high neutral currents [2]. With an emphasis on the benefits of power electronics technology (small size, efficiency, better control), harmonic distortion of the power system is inevitable and special procedures need to be put in place to limit harmonics to allow networks and equipment to

V. J. Gosbell is with the University of Wollongong (e-mail: v.gosbell@uow.edu.au).

R. A. Barr is a consulting engineer with Electric Power Consulting Pty Ltd (e-mail: rbarr@epc.com.au). operate as intended.

One of the main international documents addressing this issue is IEC 61000-3-6 [3], a technical report developed and published by the International Electrotechnical Commission. A major concept is the Compatibility Limit for harmonic voltage, intended as the boundary between the maximum level to be allowed on networks (Planning level) and the minimum level at which equipment will malfunction (Immunity level). These limits reduce with increasing harmonic order. Although most power system harmonic distortion is caused by customer loads, [3] gives the major responsibility for controlling harmonics to the network owner since they are in the best position to coordinate customer harmonic emissions.

The IEC report [3] recommends Planning levels for different parts of power systems. At MV voltage levels and above, customers can be expected to be responsible for their plant emissions. Network owners are required to determine, for each harmonic, the maximum current which each customer can inject. These limit values can form part of a network connection agreement.

This paper will concentrate on the MV allocation process. The IEC document gives some general principles, but these can be very difficult to implement in practice. Another approach is given in the IEEE standard [2] with harmonic currents given in a very simple tabular form. A difficulty with this is that the detailed methodology of determining the table is not well described and it is not clear how to extend it to networks based on European practices including the meeting of the rather different IEC Planning levels.

Although given the status of a technical report, [3] has been adopted as a full standard by the Australian national regulatory authorities and they have asked that all network owners abide by it. Consequently there has been incentive in Australia to develop detailed approaches to MV allocation process. References [4] and [5] attempt to detail the allocation process for different situations. Standards Australia has published HB2642003 [6] as a guide to the use of both the harmonic and flicker standards in radial distribution systems.

This paper is a continuation of the above work and will review the IEC approach and then propose a new approach, aimed at meeting the IEC general principles. This approach is based on the concept of the system "voltage droop" which will be discussed below and leads to an allocation dependent only on the maximum demand (called "agreed power" in IEC standards) and fault level of the assessed installation. The approach is as simple as the IEEE to implement, but has a more rigorous theoretical basis and can be adapted for 
different types of systems and different harmonic limits.

The success of the method depends on all shunt capacitors being detuned, but this is an essential requirement for any harmonic allocation method so far described. Under these conditions, the system harmonic reactance is simply

$$
\mathrm{x}_{\mathrm{h}}=\mathrm{hx}_{1}
$$

Section III of the paper will summarise the IEC guidelines and argue that there is not yet a satisfactory procedure for applying them to practical situations. The voltage droop concept, which is the subject of a companion paper [7], will be briefly described in Section IV. It will then be shown how it can simplify harmonic allocation following IEC guidelines including an allowance for diversity. The following section will give an alternative form for the allocation equation using Short-circuit Ration (SCR) allowing the new approach to be related conveniently to IEEE-519 allocation tables. Finally we discuss further refinements which could be made to this harmonic allocation approach.

\section{SUMMARY OF IEC APPROACH [3]}

\section{A. Analysis principles}

Normally harmonic quantities vary with time and are described by their 95\% cumulative probability value. When we refer below to a harmonic voltage $V_{h}$, the $95 \%$ value is intended unless otherwise stated. Diversity is represented by an exponential summation law. For example, if two independent sources give harmonic voltages of $V_{1 h}$ and $V_{2 h}$ separately, the voltage due to their combined effect is assumed to be

$$
\mathrm{V}_{\mathrm{h} . \mathrm{tot}}=\sqrt[\alpha]{\mathrm{V}_{1 \mathrm{~h}}^{\alpha}+\mathrm{V}_{2 \mathrm{~h}}^{\alpha}}
$$

where $\alpha$ has a value depending on the harmonic order $h$, and in particular has the value of 1.4 for $5 \leq h \leq 10$.

\section{B. Allocation principles}

Each load is to be given an equitable allocation (this idea will be developed below). In a particular MV subsystem, when the system is fully loaded, the maximum harmonic voltage in the subsystem is to be equal to the Planning level. This implies that all available harmonic voltage is allocated to all the customer loads which are expected to be connected with nothing held in reserve for contingencies.

Suppose the Planning level for harmonic $h$ at $M V$ is $L_{M V h}$. Not all of this is available for the locally connected MV loads because of the contribution from upstream loads and from LV loads connected to the local system. The determination of the available voltage is given in [3] and has the symbol $\mathrm{G}_{\mathrm{MVh}}$.

At harmonic $\mathrm{h}$, the harmonic current allocated to a load having maximum demand $\mathrm{S}$ varies as $\mathrm{S}$. When there is diversity, it is found convenient to allocate a current increasing as $\mathrm{S}^{1 / \alpha}$. The reason for this can be seen by considering the special case of an MV substation with all loads connected directly to output bus. Adding the voltages taken to the power of $\alpha$ is then equivalent to adding $S$ terms directly. This leads to the allocation law for this case of

$$
\mathrm{E}_{\mathrm{Uhi}}=\mathrm{G}_{\mathrm{MVh}}\left(\frac{\mathrm{S}_{\mathrm{i}}}{\mathrm{S}_{\mathrm{t}}}\right)^{1 / \alpha}
$$

where $E_{\text {Uhi }}$ is the harmonic voltage allocated to load $S_{i}$ and $S_{t}$ is the sum of all the MV loads to be given an allocation. The harmonic current is then allocated depending on the harmonic impedance at the point of load connection. In the case where all nearby capacitors are detuned, if the fundamental impedance at the supply point is $\mathrm{x}_{\mathrm{i} 1}$, the allocated current will be

$$
\mathrm{E}_{\mathrm{Ihi}}=\frac{\mathrm{E}_{\text {Uhi }}}{\mathrm{hx}_{\mathrm{i} 1}}
$$

This allocation procedure is unsatisfactory in the more usual case when MV loads are distributed along MV feeders where, typically fault levels can vary by 10:1 or more. Consider the case of two loads $\mathrm{A}$ and $\mathrm{B}$, having identical maximum demand $\mathrm{S}$, with A connected very close to the MV supply point and $\mathrm{B}$ connected at the far end where the fault level is 10 times smaller. Application of $(3,4)$ would give equal voltage and a current 10 times different to the two loads.

An alternative strategy is to allocate equal harmonic currents rather than equal harmonic voltages to two equal loads. This could be achieved by an allocation law

$$
\mathrm{E}_{\text {Ihi }}=\mathrm{k}_{\mathrm{h}} \mathrm{S}_{\mathrm{i}}{ }^{1 / \alpha}
$$

$\mathrm{k}_{\mathrm{h}}$ is a constant called the "allocation constant" for the particular MV power system and is determined by finding the harmonic voltage contribution for each load from the inverse of (4), summing them using the summation law and equating the result to the available voltage $\mathrm{G}_{\mathrm{MVh}}$. For the case of zerolength feeders it is easy to see that

$$
\mathrm{k}_{\mathrm{h}}=\frac{\mathrm{G}_{\mathrm{MVh}}}{\mathrm{hx}_{1} \mathrm{~S}_{\mathrm{t}}{ }^{1 / \alpha}}
$$

while for the more general case, $\mathrm{k}_{\mathrm{h}}$ is much more difficult to determine, since combining the voltages from all connected MV loads now requires data for the magnitude and connection point of all locally-connected loads to be accounted for, including future loads whose details might be unknown at the time that a specific allocation has to be determined.

The harmonic current allocation approach appears to be more equitable, however another difficulty arises. Where the fault level at B is very low, this load has to be allocated a small harmonic current. Load A is restricted to the same low allocation, no matter how strong is its point of supply. The cost of achieving equitability is to under-utilise the harmonic absorption capacity of the power system.

Reference [3] shows an effective compromise which is mid-way between voltage and current harmonic allocation the allocation of harmonic VA. This can be expressed in the form

$$
\mathrm{E}_{\mathrm{Ihi}}=\mathrm{k}_{\mathrm{h}} \frac{\mathrm{S}_{\mathrm{i}}{ }^{1 / \alpha}}{\sqrt{\mathrm{x}_{\mathrm{i} 1}}}
$$

where $\mathrm{k}_{\mathrm{h}}$ is an allocation constant different in value to that in (5). In the above case, load B will be allocated a current only $\sqrt{ } 10$ smaller than that for load $A$, while the harmonic voltage at the point of connection will be correspondingly $\sqrt{ } 10$ times 
larger. This allocation strategy is thus more equitable than voltage allocation, and allocates more harmonic current than does current allocation. Again, the determination of $\mathrm{k}_{\mathrm{h}}$ requires a harmonic loadflow of the system including all future loads.

\section{Difficulties with present IEC approach}

Whether harmonic voltage, current or VA allocation is adopted, the difficulties are similar and have been described in detail in [5]

- The data requirements are large, being the magnitude and impedance at the point of connection for each significant MV load.

- Assumptions need to be made about the position and point of connection of future loads.

- Assumptions need to be made of the impact of LV loads on the MV system.

- Meshed systems cannot be solved easily by simple tools such as spreadsheets.

A range of assumptions gives a range of allocated currents, and this can create difficulties in dealing with customers. Utilities are responsible for controlling the system harmonic voltage and would tend to be conservative in allocating harmonic current. Customers wish to avoid mitigation costs and would prefer a scenario giving a large harmonic current allocation.

A solution to this dilemma is one which minimizes the need to make assumptions about present and future loads. We shall show that the voltage droop concept provides an allocation strategy with this property, as well as being applicable to any power system topology.

\section{PRoposed APPROACH BASED ON VOLTAGE DROOP CONCEPT [7]}

\section{A. Voltage droop}

When a large load is suddenly connected to a power system, there is a relatively large initial voltage reduction related to the load current and the system fundamental impedance. If the voltage change is sufficiently large, On Load Tap Changing (OLTC) transformers will operate to keep steady state voltages throughout the network within acceptable ranges. The voltage change between the load side of the first OLTC transformer above the load and the load itself is called Voltage Drop. Voltage Drop is related to the system impedance between the load and the first upstream OLTC transformer. With the exception of Line Drop Compensation schemes, Voltage Drop cannot be corrected by OLTC operation. In contrast to Voltage Drop, Voltage Droop is associated with the total initial voltage reduction. Voltage Droop is related to the total system Thevenin impedance which is larger than that associated with Voltage Drop. Depending on the configuration of the network, a large part of the Voltage Droop will normally be counteracted by OLTC operation.

A distorting load draws harmonic current and creates a harmonic voltage drop in the power system. This harmonic voltage is related to the system Thevenin harmonic impedance. If capacitors are unimportant (either they are absent or detuned), this impedance is the fundamental Thevenin impedance scaled up by the harmonic order " $h "$. This idea gives the link between harmonic allocation and voltage droop.

Several types of voltage droop can be identified. The above discussion concerned load voltage droop. Feeder voltage droop is the combination of the voltage droops of all the loads either directly connected to the feeder under review or impacting on it by means of spur connections. This value is limited by system planners indirectly by voltage drop and network loss considerations. The value must be such that the combination of all upstream voltage regulators will keep the voltage within the acceptable range. This limiting value we shall call the System voltage droop with symbol $\mathrm{V}_{\text {droop. }}$ For Australian distribution systems, preliminary work suggests that a typical value is $30-40 \% \mathrm{pu}$.

Consider a load $\mathrm{S}_{\mathrm{i}}$ connected to an unloaded MV feeder at a point where the fundamental Thevenin reactance is $x_{i 1}$. The load voltage droop seen at the point of connection through to the end of the feeder is $\mathrm{x}_{\mathrm{i} 1} \mathrm{~S}_{\mathrm{i}}$.

$$
\mathrm{V}_{\text {droop. } \mathrm{i}}=\mathrm{S}_{\mathrm{i}} \mathrm{x}_{\mathrm{i} 1}
$$

The aim of the new allocation approach is to form an allocation equation related to (8) so that the harmonic voltage is related to the voltage droop. The major difficulty in this development is to allow for diversity.

\section{B. Case with no diversity for harmonic quantities}

Let us assume that every load is given an allocated harmonic current proportional to its fundamental current. In per unit

$$
\mathrm{E}_{\text {Ihi }}=\mathrm{k}_{\mathrm{h}} \mathrm{S}_{\mathrm{i}}
$$

This load then gives a harmonic voltage drop contribution of

$$
\mathrm{V}_{\mathrm{ih}}=\mathrm{k}_{\mathrm{h}} \mathrm{S}_{\mathrm{i}} \mathrm{hx}_{\mathrm{i} 1}=\mathrm{k}_{\mathrm{h}} \mathrm{h}\left(\mathrm{S}_{\mathrm{i}} \mathrm{x}_{\mathrm{i} 1}\right)
$$

Thus for each fundamental voltage drop in the system, there will be a corresponding harmonic voltage drop $\mathrm{k}_{\mathrm{h}} \mathrm{h}$ times larger. Hence we can write

$$
\mathrm{V}_{\mathrm{h}}=\mathrm{k}_{\mathrm{h}} \mathrm{hV}_{\mathrm{d}}
$$

This will lead to a maximum harmonic voltage contribution to the network equal to $\mathrm{k}_{\mathrm{h}} \mathrm{h}$ times the load maximum fundamental voltage droop contribution. When aggregated across all customers, the total harmonic voltage at the extremities of the power system becomes limited by the maximum network voltage droop. In order to ensure that the maximum harmonic voltage is acceptable

$$
\mathrm{L}_{\mathrm{LVh}} \geq \mathrm{k}_{\mathrm{h}} \mathrm{hV}_{\mathrm{d} \text { roop }}
$$

To limit the harmonic voltage and allow the system to be fully loaded (in the harmonic sense), we chose

$$
\mathrm{k}_{\mathrm{h}}=\frac{\mathrm{L}_{\mathrm{LVh}}}{\mathrm{hV}_{\mathrm{d} \text { roop }}}
$$

\section{Diversity represented by the summation law}

For reasons which will become apparent below, we modify (9) to give 


$$
\mathrm{E}_{\mathrm{Ihi}}=\mathrm{k}_{\mathrm{h}} \frac{\mathrm{S}_{\mathrm{i}}^{1 / \alpha}}{\mathrm{x}_{\mathrm{i} 1}{ }^{1-\frac{1}{\alpha}}}
$$

Suppose that each load is taking up its full harmonic allocation. The maximum load harmonic current $\mathrm{I}_{\mathrm{ih}}$ is then given by (14). The corresponding harmonic voltage contribution at the point of connection and at any point downstream from there to the network extremities is

$$
\mathrm{V}_{\text {ih }}=\mathrm{I}_{\text {ih }} \mathrm{hx}_{\text {ih }}=\mathrm{k}_{\mathrm{h}} \mathrm{h}\left(\mathrm{S}_{\mathrm{i}} \mathrm{x}_{\mathrm{il}}\right)^{1 / \alpha}
$$

First consider the case where the MV subsystem has only one feeder. The harmonic voltage at the end of the feeder is found by adding terms like (15) taken to the power of $\alpha$, that is terms like

$$
\mathrm{V}_{\text {ih }}^{\alpha}=\left(\mathrm{k}_{\mathrm{h}} \mathrm{h}\right)^{\alpha} \mathrm{S}_{\mathrm{i}} \mathrm{x}_{\mathrm{i} 1}
$$

We see that the harmonic voltages to the power of $\alpha$ are now proportional to the voltage droop contributions. When these terms are all added

$$
\mathrm{V}_{\mathrm{h}}^{\alpha}=\left(\mathrm{k}_{\mathrm{h}} \mathrm{h}\right)^{\alpha} \mathrm{V}_{\mathrm{d}}
$$

In order to limit the harmonic voltage at the end of LV feeders, $k_{h}$ should be chosen from

$$
\mathrm{k}_{\mathrm{h}}=\frac{\mathrm{L}_{\mathrm{LVh}}}{\mathrm{hV}_{\mathrm{d} \text { roop }} 1 / \alpha}
$$

For example, for $\mathrm{h}=5, \mathrm{~L}_{\mathrm{LVh}}=5.5 \%, \mathrm{~V}_{\text {droop }}=30 \%, \mathrm{k}_{\mathrm{h}}$ is taken as 0.026 .

When there are several feeders, it is not possible to derive (18) in a rigorous a manner. The difficulty is due to the equation for the harmonic voltage due to one source acting through several impedances in series. These voltages add directly, not using the summation law. As a consequence, the harmonic voltage drops throughout the network no longer exactly correspond to the fundamental voltage drops.

We have studied several cases to find the error due to the use of (18) in multi-feeder systems. There is only room here to give brief conclusions

- The use of (18) always leads to harmonic voltages being less than the desired limit, so the systems absorption capacity is not fully utilised.

- For a given source impedance, as the feeder length increases, the error at first grows and then decreases. The error is a maximum when the feeder impedance is about five times the supply impedance.

- The error increases with the number of feeders.

In particular, we have studied the error for a typical Australian suburban system where the zone substation supplies about ten feeders whose impedance is about ten times the source impedance. For this case, the error is $20 \%$, which is acceptable for these studies and gives some reserve against uncertainties such as the future connection of embedded generation. The method given in [5] might appear to be more accurate because of the detailed modelling required, but in practice much of the data has to be guessed. Another factor is that the present method requires a very simple calculation and is very robust against computational error.

\section{Example}

What $5^{\text {th }}$ harmonic current should be allocated to a $500 \mathrm{kVA}$ installation connected to an MV power system where the fault level is $62.5 \mathrm{kVA}$ ? The LV Planning level is taken as 5.5\% and diversity is assumed to be represented by $\alpha=1.4$. The maximum network voltage droop at the network extremities is $30 \%$.

Solution: Using a base of 1MVA, $S_{i}=0.5 \mathrm{pu}, \mathrm{x}_{\mathrm{i} 1}=0.016$ pu and

$$
\mathrm{E}_{\text {Ihi }}=\mathrm{k}_{\mathrm{h}} \frac{\mathrm{S}_{\mathrm{i}}{ }^{1 / \alpha}}{\mathrm{x}_{\mathrm{i} 1}{ }^{1-\frac{1}{\alpha}}}=0.026\left(\frac{0.5^{1 / 1.4}}{0.016^{1-\frac{1}{1.4}}}\right)=0.052 \mathrm{pu}
$$

giving a $5^{\text {th }}$ harmonic current of $10.3 \%$ of the fundamental current. The form of (14) gives less percentage harmonic current with increased load size, and we will investigate this in more detail later.

Note the following issues

- The maximum end of LV feeder voltage droop is the correct figure to use irrespective of where the assessed load is connected.

- The data required for each allocation calculation is just two numbers, the load's maximum demand and the fundamental reactance at the point of connection.

- The result applies irrespective of the power system topology - simple radial, radial with spurs or mesh.

There is a close relationship between the proposed new allocation procedure and harmonic VA allocation. It can be seen that (14) is very similar in form to (7), the difference being the exponent of $x_{i 1}$ which is listed in Table 1. For low frequency harmonics, where there is no diversity, there is no variation with fault level. For the common harmonic range $5 \leq \mathrm{h} \leq 10$, this power is 0.29 , compare with 0.5 for harmonic VA, giving harmonic allocations slightly less sensitive fault level than the harmonic VA policy. At high frequencies, this power is exactly the same as for the harmonic VA approach, with the allocation constant now found immediately rather than from an extensive harmonic loadflow calculation.

TABLE I

VARIATION OF DENOMINATOR EXPONENT WITH HARMONIC RANGE

\begin{tabular}{|l|l|l|}
\hline $\mathrm{h}$ range & $\alpha$ & $1-\alpha^{-1}$ \\
\hline $\mathrm{h}<5$ & 1 & 0 \\
\hline $5 \leq \mathrm{h} \leq 10$ & 1.4 & 0.29 \\
\hline $10<\mathrm{h}$ & 2 & 0.5 \\
\hline
\end{tabular}

\section{DEPENDENCE ON SHORT-CIRCUIT RATIO}

\section{A. Allocation equation}

The SCR or short-circuit ratio of a load is defined as the ratio of the fault level at the point of connection divided by the load maximum demand.

$$
\mathrm{SCR}_{\mathrm{i}}=\frac{\text { fault_level }}{\mathrm{S}_{\mathrm{i}}}=\frac{1}{\mathrm{~S}_{\mathrm{i}} \mathrm{x}_{\mathrm{i} 1}}
$$

For the present study, it is important that the SCR value is related to the reactance component of the total system impedance. This relationship is not so simple in weak MV and LV systems where the resistance component of the impedance 
is significant. Here the fault level value in (19) might have to be increased from the actual value to more truly reflect the value of $\mathrm{x}_{\mathrm{i} 1}$.

Substitution of (19) into (14) gives

$$
\mathrm{E}_{\text {Ihi }}=\mathrm{k}_{\mathrm{h}} \mathrm{S}_{\mathrm{i}} \mathrm{SCR}_{\mathrm{i}}{ }^{1-\frac{1}{\alpha}}
$$

We now express the allocated current as a fraction of the fundamental current by dividing by $S_{i}$ giving

$$
\frac{\mathrm{E}_{\mathrm{Ihi}}}{\mathrm{I}_{\mathrm{i} 1}}=\mathrm{k}_{\mathrm{h}} \mathrm{SCR}_{\mathrm{i}}{ }^{1-\frac{1}{\alpha}}
$$

Another useful equation is the variation of the harmonic voltage at the point of connection with the supply, given by multiplying (14) by the harmonic impedance $\mathrm{hx}_{\mathrm{i} 1}$ and then eliminating $\mathrm{x}_{\mathrm{i} 1}$ using (19).

$$
\mathrm{E}_{\text {Uhi }}=\mathrm{k}_{\mathrm{h}} \mathrm{h} \times \mathrm{SCR}_{\mathrm{i}}{ }^{-\frac{1}{\alpha}}
$$

Equation(21) has been graphed in Fig. 1 using a log/linear graph for $\mathrm{h}=5$ giving a percentage harmonic current increasing as SCR to the power of 0.29 . This slowly varying function appears to increase more quickly in the graph because of the logarithmic abscissa scale to allow representation of a wide range of SCR. We note that the percentage harmonic current approaches a minimum value of $2.6 \%$ at low values of $\mathrm{SCR}$. We have added points corresponding to SCR values for typical conditions of a weak MV system $(\mathrm{SCR}=8)$, a strong MV system $(\mathrm{SCR}=100)$, a personal computer in a suburban house $(\mathrm{SCR}=800)$ and a compact fluorescent lamp $(\mathrm{SCR}=30,000)$. This highlights that this concept applies for both installations and individual items of equipment. We see that MV allocations should lie in the range of $4-10 \%$, PCs should expect to draw about $17 \% 5^{\text {th }}$ harmonic current and CFLs about $43 \% 5^{\text {th }}$ harmonic current.

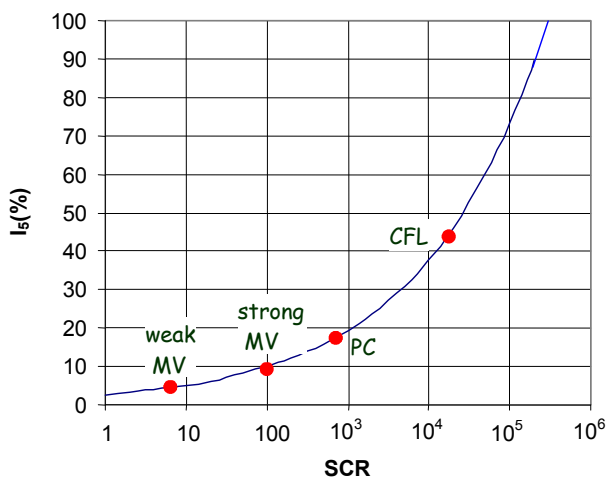

Fig. 1 - Variation of allocated current with

Note that actual equipment standards for PCs and CFLs would not be expected to have exactly these values. These standards have been determined based on assumptions that may not exactly match the summation law with $\alpha=1.4$. Nevertheless they are a good reference point in the absence of any other information. In particular, this approach may be worth considering for the LV installation standards which are at present being developed by some authorities.

\section{B. Comparison with IEEE 519 allocation procedure}

IEEE 519 [2] directly expresses the percentage current allocation in terms of SCR in tabular form. The IEEE limits are different $\left(3 \%\right.$ at the $5^{\text {th }}$ harmonic) and $k_{h}$ has been recalculated as 0.0142 . We have tentatively assumed a voltage droop of $30 \%$. A comparison between the two approaches is given in Fig. 2.

An exact match between a tabular approach and a single equation cannot be expected. With this reservation, we note that the new approach gives an allocation procedure varying with SCR in a very similar way. In general, the IEEE approach gives a higher allocation. It is possible that a smaller value of voltage droop is applicable in the USA, in which case the smooth graphed would be scaled up to give even closer agreement. Alternatively, it is possible that the IEEE approach assumes that not all customers take their full allocation, in contrast with IEC guidelines.

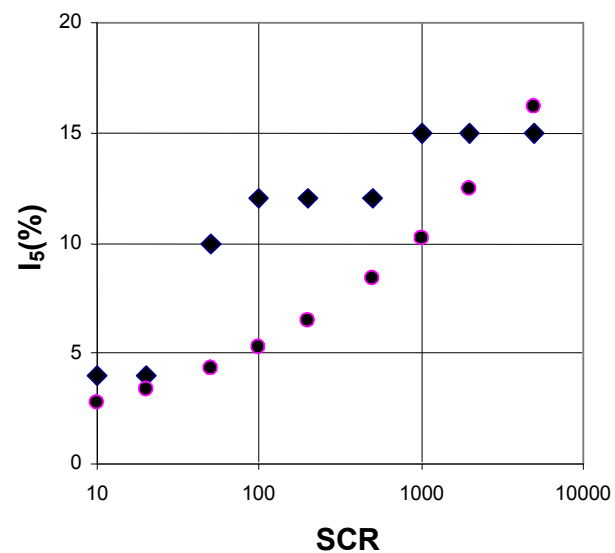

Fig. 2-Comparison of IEEE 519 and proposed new allocation procedure.

(IEEE $\bullet$, Proposed $\bullet$ )

On the whole, the consistency of the two approaches is very good considering that they are compared for a range of SCR covering almost three decades. This confirms that the new approach is broadly consistent with present practices.

\section{DISCUSSION}

The work reported is only part of our investigations. We summarise some other issues that we have considered and which will be detailed in future publications.

\section{A. Triplens}

Balanced triplen harmonic currents do not flow in the same path as the fundamental and non-triplen harmonic currents. The path depends upon transformer vector groups, transformer connection arrangements and earthing practices which vary with different utilities. Nevertheless it should be possible to estimate the ratio of the "effective" fundamental reactance seen from the extremities of the LV system using positive and zero sequence impedances.

\section{B. Planning levels}

The proposed approach is based only on meeting a planning level at LV, unlike the IEC approach which gives recommended planning levels to be applied across the power system, reducing towards the higher voltage parts of the network. The new approach allows the expected harmonic voltage variation across the network to be determined so that 
the state of the system can be assessed following a harmonic survey campaign. Because of the form of the summation law, harmonic voltage levels fall slowly from LV to MV and then more quickly as the higher voltage levels are approached. Thus the harmonic voltages which would result are very similar to the IEC planning levels and this confirms that the approach is close to the IEC guidelines.

There are doubts that the recommend IEC Planning levels can be used in all system types - for example some Australian SWER (Single Wire Earth Return) systems which have high MV impedances and low LV impedances. The new approach applies here since the essential aim is to meet a compatibility level at the end of the extremities of the system, not to meet a specified harmonic voltage profile across different voltage levels.

\section{Accounting for previous history}

Due to the prior use of other standards, or possibly no standards at all, the harmonic levels in a power system might develop differently than if every installation met an allocation following (14). It may not be satisfactory to change immediately to a new method of harmonic allocation if there has been a significant over-allocation or under-allocation in the past. An approach needs to be developed where there are pre-allocation measurements to assess the impact of previous allocation schemes and then a corresponding correction to (14).

\section{Flicker allocation}

Finally we discuss the ramifications for flicker allocation which differs from harmonic allocation in several ways

- Only a fraction of loads require a flicker allocation

- Flicker diversity is represented by an exponential summation law using an exponent $\mathrm{m}$ whose value is often taken as 3 .

- The determination of flicker voltages involves both resistive and reactive impedance components and changes in both load P and Q.

A flicker allocation scheme could be developed following (22) where $E_{U h i}$ is replaced by $E_{\text {Psti }}$ for short term flicker allocation (a similar term for long term flicker allocation), $\mathrm{h}$ is replaced by a multiplier to account for impedance angle and power factor effects and $\alpha$ is replaced by $\mathrm{m}$.

\section{CONCLUSIONS}

Present IEC guidelines are difficult to apply to realistic cases because of the data load, the number of assumptions and the computational complexity. A new approach based on the voltage droop concept is proposed. Its implementation requires that all shunt capacitors are effectively detuned. The benefits of the approach are a simple calculation with minimal data and very few assumptions. It applies to radial or meshed distribution systems where feeders are sufficiently short that line capacitance can be ignored. It also applies to non-standard power systems such as rural SWER type systems.

The approach can be applied at the installation (MV or LV) and the equipment level. Although equipment standards may be based on very specific assumptions of diversity, the new approach can be used to give reference values. The approach is shown to be closely related to the IEEE 519 approach.

It is suggested that the concept could be applied to other power quality allocation studies such as flicker and unbalance, but much work needs to be done in this area before useful results can be found.

\section{REFERENCES}

[1] AS 2279.2 "Disturbances in mains supply networks. Part 2: Limitations of harmonics caused by industrial equipment", Standards Australia, first published 1979.

[2] IEEE Std 519-1992, "IEEE Recommended practices and requirements for harmonic control in electrical power systems", IEEE 1992

[3] IEC/TR 61000-3-6 "Electromagnetic compatibility (EMC) - Part 3-6: Limits - Assessment of emission limits for the connection of distorting installations to MV, HV and EHV power systems", IEC, Ed 2, 2008

[4] V.J. Gosbell and D Robinson, "Allocating harmonic emission to MV customers in long feeder systems", Proc. AUPEC03, Sept-Oct, 2003, Christchurch

[5] V.J. Gosbell, "Harmonic Allocation to MV Customers in Rural Distribution Systems", Aust Journal of Electrical \& Electronics Engineering, Vol. 5, No. 3, 2009, pp.213-220

[6] V.J. Gosbell, S. Perera, V. Smith, D. Robinson and G. Sanders, "Power Quality - Recommendations for the application of AS/NZS 61000.3.6 and AS/NZS 61000.3.7", Standards Australia, HB 264-2003, August 2003, ISBN 0733754392

[7] R.A. Barr and V.J. Gosbell, "Introducing Power System Voltage Droop as a New Concept for Harmonic Current Allocation", IEEE, International Conference on Harmonics and Quality of Power, Sept, 2010, Bergamo, Italy.

\section{BIOGRAPHIES}

Vic Gosbell (M'1975) obtained his BSc, BE and PhD degrees from the

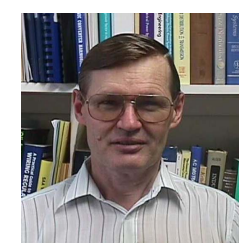
University of Sydney. He has held academic positions at the University of Sydney and the University of Wollongong where he became the foundation Professor of Power Engineering. He is now Emeritus Professor and Technical Advisor to the Integral Energy Power Quality and Reliability Centre. He is currently working on harmonic management, power quality monitoring and standards. He is a member of Australian standards and CIGRE sub-committees and is a Fellow of the Institution of Engineers, Australia.

Robert Barr (M'1993) is a consulting engineer and director of his company

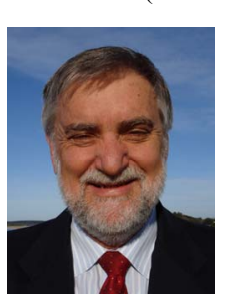
Electric Power Consulting Pty Ltd. Robert holds an Honours degree in Electrical Engineering from Sydney University, a Master of Engineering degree from the University of NSW and a PhD in electrical engineering from the University of Wollongong. Robert has over 36 years experience in the field of electricity distribution and is a fellow of the Institution of Engineers Australia, a member of Consult Australia and National President of the Electric Energy Society of Australia. 